Of the more permeable rocks constituting the first list, probably four-fifths of the area would yield unpolluted water, and receive into its mass not less than six inches of rainfall annually, or a quantity, if all yielded up to wells, of no less than 240,000 gallons per day for each square mile of area.

Of the second list the rocks are for the most part impermeable, and the most porous portion of the carboniferous generally return the water that has percolated into the strata to the same river basin; these rocks receive the heaviest rainfall of England, seldom falling below forty inches, and often rising to more than a hundred, of which quantity not less than thirty inches per annum may safely be calculated on, as the quantity run off by streams. Assuming that the rainfall is only available for water supply purposes, over one-tenth of the area, or 2, I53 square miles, and that onethird of the supply is given back to the streams as compensation to manufacturers, to preserve fish, and for the purposes of inland navigation, the quantity remaining off this selected tract would be more than sufficient for the whole population of England, without recourse to the subterranean supply, which Dr. Frankland more especially recommends for domestic use; so that there can be no shadow of doubt that the quantity of water available for supply to towns and rural populations, of a standard of purity approved by Dr. Frankland, is far in excess of the requirements of our population.

The question of the amount of compensation water which should be returned to streams which are impounded for the purpose of water-supply is one of the gravest national importance. In one case, the River Roddlesworth, taken by the Liverpool Corporation Waterworks, the Legislature permitted "the compensation water," ordered to be returned to the stream by the Act of 1847 , to be bought up, for the purpose of supplying a new reservoir, and thus deprived the district drained by the stream, in the words of Mr. Bateman, speaking of a similar proposal," " of all possible participation in the extension of manufactures and in the commercial prosperity of the surrounding district." Mr. Bateman has strongly expressed similar views in his evidence before the Duke of Richmond's Commission, and it is with regret, we notice that though he proposes to take eventually 50 million gallons per day from Thirlmere, he only intends to return $5^{\frac{1}{2}}{ }^{2}$ million gallons a day to St. John's Beck.

On the second head, the necessity of legislation to give cheaper and more easily acquired water powers to sanitary authorities, through the agency of provisional orders of the Local Government Board-which do not now possess compulsory powers to acquire water-rights, under the Local Government Act of 1875. Mr. A. H. Brown, M.P., read a paper describing the work done by the Select Committee on the Public Health Amendment Bill, of which he was chairman, and which has now been read a third time in the House of Commons and passed. The Bill introduces many sweeping changes, and not only gives to the Local Government Board increased powers, but empowers them "to confer the powers of this Bill or any of them to urban authorities," and further ordains that the Board shall have power to permit Local Boards to purchase water compulsorily, under provisional orders, confirmed by Parliament, "such Provisional Orders to put in force the Water Clauses Act, $x$ 847."

Should Mr. Brown's Bill pass the Upper House but little additional legislation would appear to be necessary, for the labours of the various Royal Commissions, Parliamentary Committees, and the British Association Committee of Inquiry "into the Secondary rocks of England, as a source of water supply," have amassed, as we have seen,

I "Borough of Liverpool New Water Supply Report," by Mr. John Frederick Bateman, C.E., F. R.S. Liverpool, 1875 .

Frederick Bateman, C.E., lately quoted by us, is incorrect, the amount being only 5 t. a large volume of information as to the rainfall, available yield, and quality of the water suitable for domestic purposes; and the new powers obtained by the Local Government Board will enable them more quickly and cheaply to give facilities for the construction of works for water supply than heretofore. All that is still wanting, should the Bill pass, is some further machinery for ascertaining by Government inspection what rural districts and isolated hamlets are not at present properly supplied, and how the difficulty is to be solved.

The Congress have met it by passing a resolution to "urge upon Her Majesty's Government the importance of taking steps, with the least possible delay, by means of a small scientific commission to investigate and collect, for the information of the public, the facts connected with water supply, in the various districts throughout the United Kingdom, in order to facilitate the utilisation of the national sources of water supply for the benefit of the country as a whole, as suggested by H.R.H. the Prince of Wales."

The high value and important character of the work done by several bodies similarly constituted to the proposed Water Commission is so well known, that it would be needless to mention as examples the Charity, Civil Service, and Ecclesiastical Commissioners, were it not to point out that these gentlemen exercise functions of a special character, which could not well be undertaken by any other Government department; while in the case of the proposed Water Commission, this very important raison d'être appears to be absent, for special knowledge and long experience appear to be already possessed by the staff of the Local Government Board, and by that of the Geological Survey, which under the interchange system of Government officers recommended by Dr. Lyon Playfair's Commission could easily be directed to assist them, especially as to a limited extent it already does so, and has besides aided the Rivers Pollution Commission in its labours. ${ }^{1}$

The Congress has certainly been useful in showing how impossible it is to separate zuater supply from drainage, and the absolute necessity of there being a central authority, with supreme power over water, whether at the surface or underground, whether used for the purpose of water supply, canalisation, supplying motive power, or disposed of in the form of drainage and sewerage. As Dr. G. W. Child well remarked, "the bane of all local government in England is the chaos of different and often conflicting authorities, existing each for a special purpose." How the formation of the proposed permanent Water Commission will facilitate matters by adding another to the long list of governing bodies it is difficult to see.

Facts are useful; but we first want simplification and unification of the law, and the carrying out its provisions entrusted to one central authority, directed by a Minister of Public Health, with power so to modify and increase his department as to be able to collect information at the same time that he administers the law, and remove from us the possibility of the reproach that we have carried on scientific investigations to complete our knowledge of water supply, without applying, for the use of our population and the prevention of disease, the information we already possess.

\section{PHYSICAL SCIENCE FOR ARTISTS ${ }^{2}$ \\ IV.}

IM afraid there is no use in shirking the notion that my last paper may have seemed wofully dull, frightfully technical, and terribly wide of the mark to some artists who took it up, always supposing of course that

1 Annual Reports of the Science and Art Department.

Contirued ficm p. 89 
any of them did. Although I must plead not guilty to the last count, still I am so persuaded that in the nature of things these opinions were likely to be held that I feel compelled, before I go further into the experimentation with our improvised spectroscope, to draw attention to the kind of knowledge I hope to show can be gained by its use.

It might at first sight appear that, limiting ourselves to the sun as a great radiator of light, the artist has only to do with white light in his pictures. This is true in one sense, but only in one sense; for the artist has to deal with sunlight after it has been filtered through-after it has been absorbed by - many substances, notably the aqueous vapour of our air, and after reflection from others. I shall show in the sequel, for instance, precisely how it is that the sun is red at sunset; at such a time as this the sun practically gives us coloured light because our atmosphere has abstracted from it some of the constituent rays which fell on the upper air. A familiar instance of this may be referred to. The colour of a ripe cornfield, in an autumn sunset, comes from the fact that, for the moment, in consequence of this absorptive effect, our sun has been a red star instead of a white one. Cause and effect are there before our eyes, and science connects them, and yet, alas, I have seen pictures in which the grand colour of the corn has been given in perfection, while the painter has been so ignorant of the cause of it that he has given us a cold, grey, cloudy sunset, instead of a red, cloudless one.

Further, as all the ordinary colours of natural objects depend upon the way in which they reflect or absorb white light, the colours of all must change at the hour of sunset or sunrise, if the light which they usually transmit to us is wanting in the light which they then receive. An object, for instance, which appears blue at noonday will appear black if only the red light of sunset falls upon it. The blue sky over head is really a rich source of light of all colours; it is not a true blue, it is a mixture of blue and white; so that sunrise and sunset effects are much more potent when a great bank of cloud overhead leaves only the eastern or western horizon open. A striking thing for an artist to observe under this condition is the difference of luminosity of a red brick house, and such objects as trees and fields; the house seems glowing with light as if it were red hot, and for the simple reason that it gets as much light of the red kind, which is what it wants, and which it reflects to us, from the setting sun, as it does from the noonday one; whereas the trees and grass are no longer supplied with that light which they throw back to us usually, and so appear black for the same reason that lampblack appears black at noonday.

It has been a favourite theme with many astronomers to enlarge upon the marvellous coloured phenomena which must take place in those planets which are near enough to stars of strongly contrasted colours to receive their light, now from one, and now from the other, producing not only a perfect modulation and combination of the colours of both, but also the strongest contrasts, such as, for instance, the setting of a red sun followed by the opposite rising of a blue one. No doubt such phenomena would be very enthralling, but to my mind the chromatic effects produced by the aqueous vapour in our own air absorbing the various elements in the light of our single white sun when it is not more than ten degrees above the horizon, supply us with a world of beauty with which we may well be content, and I for one have not found the beauty one whit less enthralling since I have endeavoured to picture to myself the causes to which it is due.

All this, however, by way of anticipation: the causes so far as I am acquainted with them at work in the circumstances I have named, and in ten thousand others, are easily to be got at by a little simple experimentation.

In my last paper I suggested a simple form of spectro-

cope. Here is a figure which will show how the prism should be placed and what it will do to the light coming through the slit $\mathrm{C}$.

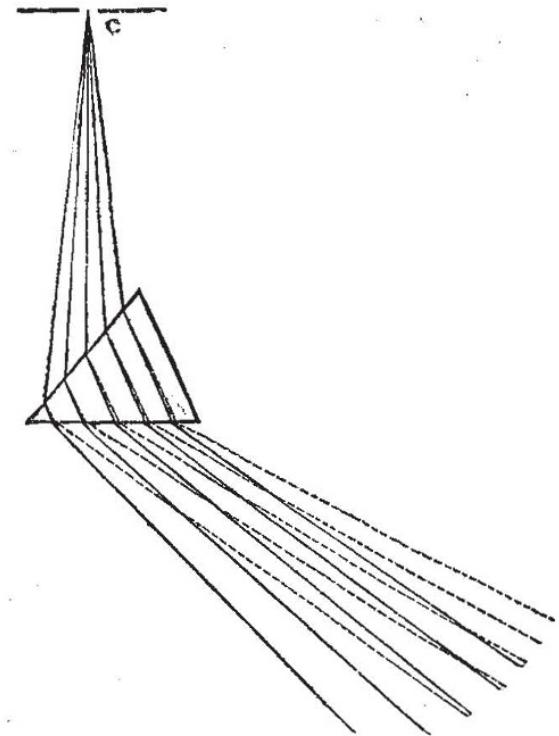

Ftc. r. -Showing arrangement of slit and prism.]

We may place a lens behind the prism as shown in Fig. 2, and throw an image on a screen, which may conveniently be a piece of white paper.

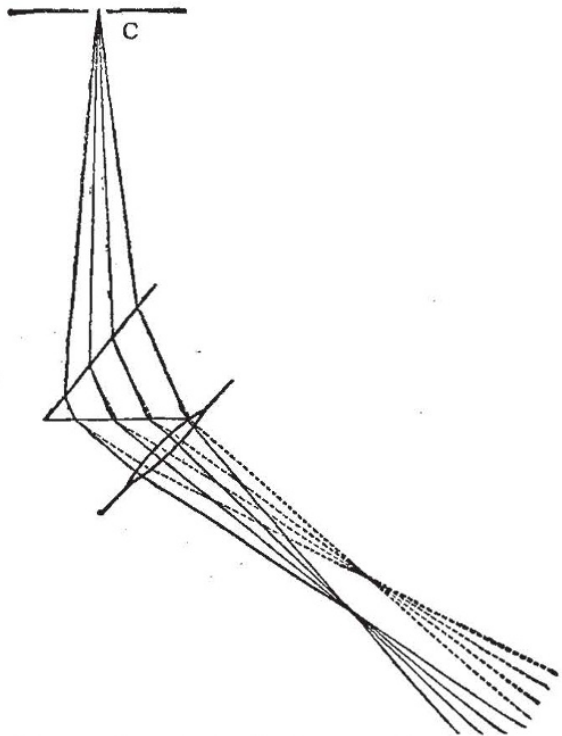

FIG. 2.-Introduction of a lens to produce an image.

If we are content to use the lens and screen which constitute the human eye it must be placed near the prism.

An expenditure of a few shillings is all that is required to enable the origin of one class of coloured phenomena to be investigated, that class, namely, in which the colour is due to the giving out, by the light source, of certain kinds of light only. This money should be expended in buying two little glass or brass tubes, $\frac{x}{10}$ inch and $\frac{1}{2}$ inch in diameter, and 5 inches long, a little glass tubing of very small bore, a few inches of platinum wire, a small quantity of red and green fire, and india-rubber tubing to convey gas from an ordinary burner to a table. Of the two tubes a Bunsen burner can be easily constructed 
This is an apparatus for burning a mixture of ordinary gas and air; the gas should be supplied through the smaller tube inserted into the lower end of the larger one, as shown in Fig. 3. The gas should be lit by holding a

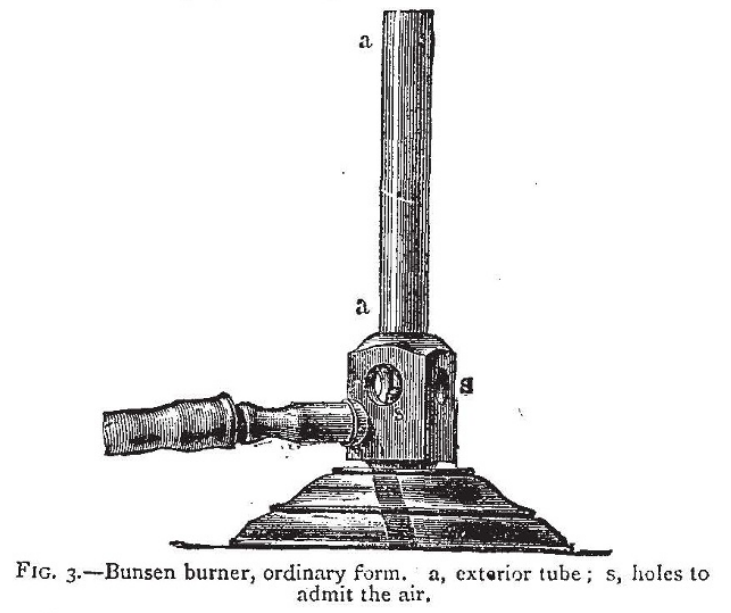

match some 4 inches above the upper orifice of the wide tube. One end of the platinum wire may be fused into

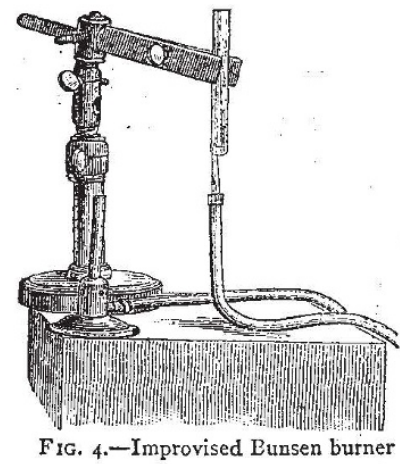

the piece of glass tubing, and the other twistedinto a loop, fine enough to hold some common salt in the flame. A piece of coke or charcoal soaked in salt and water will

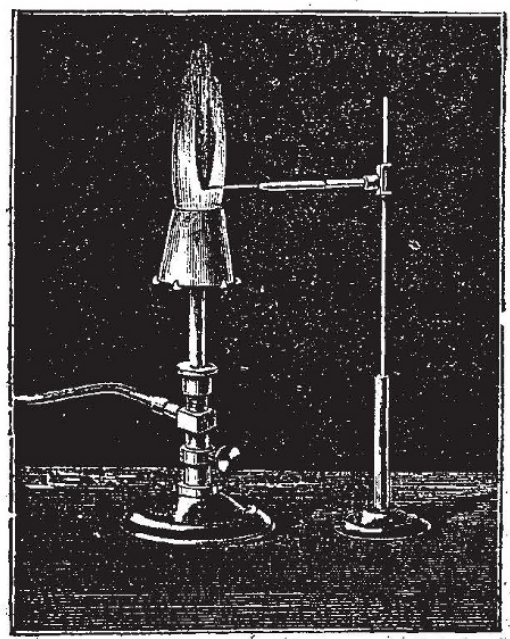

FiG. 5.-Method of inserting platinum wire and salt into the flame.

do almost as well. This tube may be supported by a"piece of wood after the fashion of Fig. 5. The Bunsen burner will give us a very hot bluish flame, into which the loop of platinum containing common salt, sodic chloride, may be inserted, as shown in the accompanying woodcut. We shall get a brilliant yellow flame, which is worth notice on its own account, and if the artist is performing these experiments in his studio, let him look at some of his choicest pictures by means of this light, before he goes any further. He will be considerably surprised at their appearance, and I hope he will set himself to think about the cause of it-a point on which there will be a good deal to be said in the sequel. It will be better, however, to get at the physics in the first instance. To do this, put the improvised Bunsen burner and the platinum wire with the salt on it in front of the slit, and look at the slit through the prism; it will be found that there is only a yellow image of the slit visible. If the things have been nicely arranged, the appearance of the spectrum will be so entirely changed that a beginner will be apt to fancy that something has gone wrong. Nothing has gone wrong however; we have simply passed from the spectrum of polychromatic to that of monochromatic light-from white light to coloured light.

These experiments touching the giving out of light can be easily and cheaply varied by burning green and red fire in front of the slit; the effect of these differentlycoloured lights on a picture is also very striking.

The next thing we bave to do then is to represent the action of an absorbing body,-to study the action of our theoretical screen-the action of bodies when they absorb light, and therefore transform the original colour which that light possessed. Liquids will form our most convenient screen to illustrate this, and they can be placed in a "cell". like that shown in the accompanying woodcut.

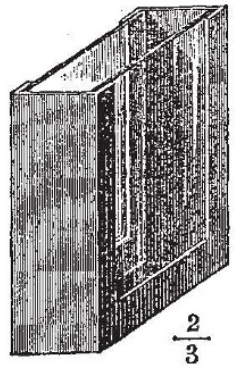

FIG. 6.-Commonfform of cell to hold solutions.

It will not be necessary to buy such an apparatus; two squares of glass, with a piece of india-rubber tubing between them, bent in the shape of a $U$; the glasses being kept in contact with the tubing by two india-rubber bands, form a cell which is wonderfully tight, and will serve our present purpose. This cell should be placed in front of the slit.

A little potassic permanganate added to the water in the cell, will act as a screen, and cut off the yellow part of the spectrum, and the adjacent regions of the orange and green. Solutions of blood or magenta will give also very definite ipdications of absorption, and if we have one of those handy little pocket spectroscopes, which now, I am glad to think, are becoming common, the absorption of the light of a candle by the blood in the lobe of a friend's ear, or in the interval between two closed fingers can be well seen by placing it between the slit and the light.

Let us now sum up as tersely as may be the conclusions at which we have so far arrived.

I. White light analysed by a prism gives us a continuous spectrum. 
II. Coloured light analysed by a prism gives us a discontinuous spectrum.

III. Light may be coloured because originally the series of its components was not complete.

IV. Light may be coloured because although the series of its components was once complete, some parts of the light have been absorbed in its passage to the eye.

$V$. The bodies which give us white light are generally complex as to their molecules.

VI. The bodies which give rise to the phenomena of bright or dark lines are generally simple as to their molecules.

I now begin, with fear and trembling, to touch upon a part of my subject in which I ought to be the first to acknowledge that our ideas are not of the sure and certain kind. In what has gone before I have been careful to point out that, though the effect of incandescent bodies in producing and absorbing light was not likely to be directly applied by the artist, it was still in this sure and certain region that he should endeavour to follow the workings of laws clearly made out which might be in force elsewhere.

This brings me to state that in my opinion the colours of most natural bodies depend upon the fact that there are definite molecular states of all kinds of matter lying between those two extreme stages to the phenomena presented by which attention has been directed. Some years ago, in a communication to the Royal Society, I drew attention to evidence which seemed to indicate that many substances which emit under certain conditions a white light giving a continuous spectrum, and coloured light associated with the spectrum of lines under others, exist also in molecular groupings between these extreme conditions, giving us for one grouping a continuous spectrum at the red end, and for the other a continuous spectrum in the blue.

This is the most general statement that I can make, and I make it on account of the utility of such a statement. It has not yet been proved to be universally true, but the evidence I have already accumulated justifies me in setting it up as a working hypothesis. Not least valid among the lines of evidence on which I rely is the curious fact that the colours of almost all natural bodies can be at once explained by assuming them to be built up of these two molecular groupings to wiich I have called attention.

Let us take gold as an instance. It is yellow; but why is it yellow? Because the molecules of gold, as I believe, generally exist in two complexities, one of them competent to harmonise with the red rays of light, and therefore to absorb them, the other doing the same thing with the blue light, and for the same reason.

Gum a piece of gold leaf on a piece of glass for easy manipulation, and look at a bright light through it; it will be seen that the gold is green, or, in other words, that the blue and red have been absorbed, we have

changed into

$$
\text { VI } B \text { (O) (O) }
$$

\section{VIB $C Y O R$}

by one set of molecules stopping

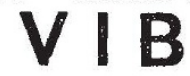

and another

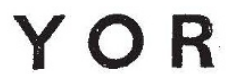

The reason that we get yellow light by reflection is that more of the central light is reflected than is transmitted.

If we do not consider reflection, the thing becomes simpler: for instance, if I take a tube one foot long and fill it with chlorine gas, and observe the spectrum of a white light through the tube, we find that chlorine absorbs only in the blue; the yellow and red are freely transmitted; a glass coloured red is so coloured because its molecules absorb the blue, and a blue glass is blue because it absorbs the red.

Prof. Stokes, in one of his lectures in South Kensington, dealt with the colours of natural bodies in connection with the absorption of light by them, and I may be permitted to close the present paper with the following extract from so great an authority :-

"What is the cause why a green leaf is green, or why a red poppy is red? It is frequently said that the reason why a red poppy is red and that a white lily is white is, that the lily reflects rays of all kinds, but the poppy reflects only the red ones, and if you place the red poppy in a pure spectrum it is luminous, like a white lily, in the red; but if you place it in the green it will be almost black, whereas the white lily will be brilliantly green. Now the common explanation, properly understood, is true; but it is not the whole truth, and if understood as it is liable to be understood, it is false. It is true that a red poppy reflects red rays, and a white lily reflects rays of all colours; but it is not true that the preference for the red to the green in the one case and the equality of action in the other takes place in the act of reflection. It is not a phenomenon of coloration by reflection. The coloured light is reflected or you would not see it; it is sent out of its course before it enters your eye, and it is true that the light, in its life's history, undergoes reflection; it is not true that it is in the act of reflection that the one colour gets the preference over the other. Here I have some solution of the colouring matter of green leaves in alcohol, and here is some more alcohol, with which I will dilute the former. I have obtained a beautiful green solution, although the green colour is not seen now by reflected, but by transmitted light. As regards the light which falls upon the surface there is a little white light reflected, just a s there would be from water, but very little is reflected from the surface where the fluid is in contact with the glass, the chief portion of that reflected being from the outer surface of the glass itself. You would not see any green at all in it unless there were something placed behind so as to reflect the light backwards. You see there that the colour of the green leaf, as ordinarily seen, is due to the combination of reflection with the phenomena of absorption, or the swallowing up of certain kinds of light when light is sent through a perfectly clear medium. I may illustrate this in another manner. Here is a vessel of water into which I will pour some blue solution. If I send light through it, it will appear of a deep blue, but if I hinder the light from coming behind, which I can do by putting black cloth behind it, it is simply dark; you do not see the blue colour at all. Why? Because there is nothing behind to reflect the light. Suppose I make it a little muddy by pouring into it some pounded chalk, you see the blue colour immediately. Why is that? You know that if powdered chalk were put into water it would not colour the fluid. But here each little particle of uncoloured chalk reflects a small quantity of light falling upon it, so that it fulfils the same office as a mirror placed behind the fluid. You may imagine that the particles of chalk are so many minute mirrors capable of reflecting light. If you take any one particle of chalk, say one-tenth of an inch deep, in the liquid, the light from the sky falls upon the fluid, it undergoes absorption in passing through that first tenth of an inch, and then the portion of light which is left is reflected by that little particle of chalk, and passes out again, and so, as regards that single particle, the light which reaches your eye from beneath that depth has itself gone through a stratum of fluid of one-fifth of an inch in thickness, and accordingly you see the colours produced by selective absorption; that is to say, by the absorption of certain kinds of light, which are more greedily devoured by the fluid than the other kinds. This is what takes place in the green leaf and in 
the petals of flowers. Let us take the white lily. If the petal of the flower had been merely a sheet of thin glass you would not have seen that white colour. There would have been a little light reflected from the first surface and the back surface, but the petal is really composed of a vast assemblage of little cells, at each of which partial reflection takes place, so that it resembles some finely-powdered glass, which would form a white powder, because each little surface is capable of reflecting the light, although a single sheet of glass would not be white. The petal of the white lily is just in the condition of the powder. It is full of little cells, full, optically speaking, of irregularities, from each of which a portion of light is reflected, so that, all kinds being reflected alike, and there being nothing in the white lily to cause preferential selection of one over the other-nothing to sift the light, as it were-you get a considerable quantity of light reflected back to the eye, but it is white. What is the difference between that and the red poppy? The red poppy is, as it were, a white lily infused with a red fluid; there is light continually reflected backwards and forwards, just as before, at the surface of the cells ; but that light, in going and coming, passes through the coloured juice of the plant. It is the same thing with a green leaf. The structure is irregular, optically considered; there are constantly reflections, backwards and forwards, of light, which penetrates a little depth and is reflected, and has to pass through a certain stratum of this colouring matter, to which the name chlorophyll has been given, but which is really a mixture. That is what takes place generally as regards the coloration of bodies; it is a phenomenon not of reflection, not of selection of one kind of light for more copious reflection than another, but of absorption, or the swallowing up of certain kinds of light. Reflection comes in in order to enable us to see the light which otherwise would not enter the eye at all, but would go off in another direction."

\section{J. NORMAN LOCKYER}

\section{COSMIC METEOROLOGY}

SEVERAL articles have appeared at different times under the title of "La Météorologie Cosmique," from the pen of M. Faye: the last and most complete forms an exceedingly interesting "Notice Scientifique," appended to the Anmuaire of the Bureau des Longitudes for 1878 . In this memoir, written with the usual clearness and talent of the distinguished French astronomer, a number of results connected with real or supposed solar, lunar, and planetary actions on our earth are examined and criticised. As M. Faye has omitted several facts of considerable importance in his "Notice," and has misunderstood others, a reconsideration of some of the questions he has studied, with the additional light to be obtained from the facts alluded to, may not be without interest and use.

M. Faye's thesis is given in the first words of his article "Meteorological phenomena have their origin in solar heat." It is added, "This is now no longer sufficient. Cosmic influences are introduced, those of the planets, of the spots and rotation of the sun, of shootingstars, the moon, and besides these, magnetic and electric actions are supposed to intervene incessantly between the bodies of the solar system." I shall refer to some of the most important questions under their different heads.

The Moon's Influence in producing Atmospheric Variations. - The popular beliefs in the moon's influence on the weather are first disposed of; they are conclusions from unrecorded observations where the coincidences are remembered and the oppositions are forgotten; and they are opposed to strict deductions when all the facts are employed.

Agreeing, as all men of science do, with this decision, the question remains, Whether the moon may not have some slight effect in producing meteorological variations? She reflects, absorbs, and radiates the solar heat; may this heat, in accordance with the thesis, not produce some effect on our atmosphere?

Sir John Herschel had observed the tendency to disappearance of clouds under the full moon; this he considered a fact which might be explained by the absorption of the radiated lunar heat in the upper strata of our atmosphere. He cited Humboldt's statement as to the fact being well known to pilots and seamen of Spanish America. I may add the testimony of Barnardin de St. Pierre, who, in his "Voyage à l'Ile de Réunion," says: "I remarked constantly that the rising of the moon dissipated the clouds in a marked way. Two hours after rising, the sky is perfectly clear" ("Avril, I768"). Herschel also cited in favour of his "meteorological fact," a result supported by the authority of Arago, that rather more rain falls near new than near full moon.

Arago's conclusion that the phenomenon was "incontestable of a connection existing between the number of rainy days and the phases of the moon "was founded on the observations of Schübler, of Bouvard and of Eisenlohr, three series which, on the whole, confirmed each other. Schübler also, as Arago showed, had found that the quantity of rain which fell was greater near new than near full moon. These results, accepted by Arago, have not been noticed by M. Faye when he cites Herschel only, as one of those "men of science who interest themselves in popular prejudices, take bravely their defence in hand and exert themselves to furnish not facts but arguments in their favour." It seems, indeed, to have been forgotten that Herschel's argument was given to explain what he considered a meteorological fact.

M. Faye founds his argument wholly on the conclusions of M. Schiaparelli from a weather register kept at Vigevano by Dr. Serafini during thirty-eight years ( $1827^{-}$ 1864). 1 The Italian physician entered the weather as clear, cloudy or mixed (misti), or rainy from morning to evening. M. Schiaparelli finds from this register that the sky was clearest in the first quarter of the moon. It has not been remarked that if the moon's heat has any effect in dissipating clouds, as Herschel and others believed, this must be seen best when the moon is near full, that is to say, during the night hours, for which Dr. Serafini's register has nothing to say. In confirmation of the conclusion that the moon does not dissipate the clouds, another result from the Vigevano weather register is cited, namely, that the greatest number of rainy days happens near full moon. This result is opposed to that derived from the observations of Schübler, Bouvard, and Eisenlohr.

The value to be given to observations of the number of rainy days must evidently depend on whether the observations include the rainy nights; and an investigation on this question, to have any considerable weight, should depend rather on the measured rainfall than on the term "rainy" day," for which no distinct definition is given.

The great objection to M. Faye's conclusions, as far as the facts go, is to be found in their entire dependence on tho Vigevano weather register (da mane a sera). No notice is taken of other observations and results showing a lunar action on our atmosphere, such as those already mentioned, which Arago considered incontestable, those of Mädler and Kreil, and the more recent investigations of Mr. Park Harrison and Prof. Balfour Stewart. All of these, and many others, must be carefully considered before we can accept the conclusion that the moon has no influence on our atmosphere. The subject is, however, too large to be entered into here at present, and it will be possible to study it better after other conclusions of the learned French Academician have been examined.

There is, however, a part of the argument, whatever the results obtained may say, which merits particular

\footnotetext{
- Menorie del R. Istituto Lombardo, L. so.
} 